\title{
Crescimento e Produção de Eucalipto na Região do Médio Paraíba do Sul, RJ
}

\author{
Dereck Halley Anthony Alves Ferreira ${ }^{1}$, Paulo Sérgio dos Santos Leles ${ }^{1}$, \\ Silvio Nolasco de Oliveira Neto ${ }^{2}$, Tafarel Rodrigues Paula ${ }^{1}$, \\ Rodolfo Pellegrini Coutinho ${ }^{3}$, Rogério Luiz da Silva ${ }^{1}$ \\ ${ }^{1}$ Instituto de Florestas, Universidade Federal Rural do Rio de Janeiro - UFRRJ, Seropédica/RJ, Brasil \\ ${ }^{2}$ Departamento de Engenharia Florestal, Universidade Federal de Viçosa - UFV, Viçosa/MG, Brasil \\ ${ }^{3}$ Instituto de Terras e Cartografia do Estado do Rio de Janeiro - ITERJ, Rio de Janeiro/RJ, Brasil
}

\begin{abstract}
RESUMO
Objetivou-se avaliar a produção de sete materiais genéticos de Eucalyptus, implantados no Município de Paty do Alferes, Rio de Janeiro. Foram utilizadas quatro espécies de eucalipto, um híbrido Eucalyptus urophylla $\mathrm{x}$ E. grandis, oriundo de sementes, e dois clones de Eucalyptus urophylla $\mathrm{x}$ E. grandis, denominados amarelo e branco. A região apresenta déficit hídrico no solo de maio a setembro. Após o plantio, foram avaliados a sobrevivência aos dois meses, o diâmetro à altura de 1,30 $\mathrm{m}$ do solo e a altura das plantas aos 18 e 80 meses. Nessa última medição, seis árvores médias de cada material genético foram abatidas para determinação do volume e da biomassa do lenho. Eucalyptus grandis, clone amarelo e Eucalyptus urophylla $\mathrm{x}$ grandis apresentaram os melhores desempenhos, sendo os mais indicados para a formação de povoamentos na região do Médio Paraíba do Sul, RJ. Eucalyptus pellita foi o que obteve menor crescimento e produção.
\end{abstract}

Palavras-chave: teste de espécies, seleção de espécies, crescimento de eucalipto.

\section{Growth and Production of Eucalypto in Region the Médio Paraíba do Sul, RJ}

\begin{abstract}
This study aimed to evaluate the production of Eucalyptus genetic materials, implanted in the town of Paty do Alferes, Rio de Janeiro. Were used four eucalyptus species, the hybrid Eucalyptus urophylla $\mathrm{x}$ E. grandis, from seedlings and two clones (yellow and white) of Eucalyptus urophylla $\mathrm{x}$ E. grandis. The region soil is water depleted from May to September. After planting, we evaluated the survival at 2 months and the diameter to the height of 1.30 meter from the ground, and total plant height at 18 and 80 months. In the latter measurement, six medium trees of each genetic material were abated to determine the volume and biomass of the wood. Eucalyptus grandis, yellow clone and Eucalyptus urophylla $\mathrm{x}$ E. grandis showed the best results, with the nominees for the formation of settlements in the region Médio Paraíba do Sul, RJ. Eucalyptus pellita showed lowest growth and yield.
\end{abstract}

Keywords: species testing, selection of species, eucalypt growth. 


\section{INTRODUÇÃO}

A formação de povoamentos florestais com espécies de crescimento rápido, como as do gênero Eucalyptus, é estratégica para aumentar a oferta de madeira e outros produtos florestais, diminuindo a pressão sobre as florestas nativas. As espécies desse gênero crescem satisfatoriamente na diversidade de condições edafoclimáticas existentes em diferentes regiões do país e apresentam ampla plasticidade de uso da madeira (Sturion \& Bellote, 2000; Martinez et al., 2012). Segundo a ABRAF (2013), esse gênero ocupa em torno de $71 \%$ das áreas das plantações florestais comerciais no Brasil. Os povoamentos de eucalipto, originados de sementes ou de propagação assexuada, são formados em grandes e médias empresas e também em pequenas propriedades rurais.

As espécies, híbridos e clones de eucalipto apresentam diferenças entre si quanto à resposta aos estímulos ambientais de cada nicho ecológico. Esses materiais, para serem utilizados em uma região hidrográfica com sucesso, necessitam da realização de testes para avaliação da sua capacidade de adaptação e produção.

Os estados de Minas Gerais e São Paulo destacam-se como os principais produtores de eucalipto, devido principalmente à grande demanda para produção de carvão vegetal e celulose, respectivamente (ABRAF, 2013). Com isso, nesses estados estão as principais pesquisas com eucalipto no Brasil, havendo necessidade de desenvolvimento de pesquisas em outros estados, devido às condições ambientais das diferentes regiões do país.

O Estado do Rio de Janeiro, apesar de possuir o segundo valor de produto interno bruto do Brasil (IBGE, 2014), não se encontra entre os 15 maiores produtores de madeira originária de plantações florestais do país (ABRAF, 2013). Segundo Amorim et al. (2012), tendo como base levantamento realizado em 2010, os reflorestamentos no Estado do Rio de Janeiro somavam apenas 18,4 mil hectares, sendo que em torno de $98 \%$ eram constituídos por eucalipto. Relatório da Poyry Silviconsult (2012) menciona que $89,4 \%$ da madeira consumida no Rio de Janeiro provêm de outros estados da federação e que para atender a demanda do consumo equivalente de madeira in natura seriam necessários aproximadamente 119,2 mil hectares de povoamentos florestais advindos de reflorestamentos, com ênfase para as espécies do gênero Eucalyptus.
A lei de Zoneamento Ecológico e Econômico (n. 5.067/2007) do Estado do Rio de Janeiro define critérios para a implantação da atividade de silvicultura e divide o estado em nove bacias hidrográficas, dentre as quais encontra-se a Região Hidrográfica RH III - Médio Paraíba do Sul (Rio de Janeiro, 2007). Segundo o levantamento da Secretaria de Estado do Ambiente do Rio de Janeiro (FIRJAN, 2013), esse espaço geográfico engloba área de aproximadamente 643.079 hectares, sendo que $44,5 \%$ foram considerados favoráveis à implantação de atividades de silvicultura. Nessa região e na Região Hidrográfica IV, que estão próximas, existe demanda elevada de madeira como fonte de energia para pizzarias, padarias e cerâmicas. Segundo Amorim et al. (2012), nessas duas regiões estão localizadas 68,3\% das áreas com povoamento de eucalipto do estado.

Alguns estudos foram realizados para testar espécies de eucalipto, como os de Gomes et al. (1981), Morais et al. (1990), Bernardo et al. (1998), Drumond et al. (1998), Coutinho et al. (2004) e Magalhães et al. (2007). Todavia, nenhum deles foi realizado no Rio de Janeiro, especialmente na região do Médio Paraíba do Sul, onde está concentrada a maior área de plantio do estado. Devido às diferenças de adaptabilidade dos materiais genéticos de eucalipto, tornam-se necessários estudos para identificar aqueles mais adaptados a essa região, bem como para desenvolver clones específicos para as características exigidas pelo mercado.

O processo de escolha de espécies de eucalipto potencialmente aptas para plantio no Brasil sempre foi baseado, primeiramente, em critérios climáticos (Barros et al., 1990; Borges, 2012). Embora o clima seja o definidor da ocorrência das espécies na sua região de origem, o solo também influência no crescimento dos materiais genéticos de eucalipto. A ocorrência de estiagem prolongada e de pragas e doenças também podem afetar a adequação das espécies em uma determinada região (Del Quiqui et al., 2001).

O objetivo deste trabalho foi avaliar o crescimento e a produção de sete materiais genéticos de Eucalytpus na região do Médio Paraíba do Sul, RJ.

\section{MATERIAL E MÉTODOS}

O experimento foi instalado no Distrito de Avelar, Município de Paty do Alferes, inserido na Região Hidrográfica do Médio Paraíba do Sul, Estado 
do Rio de Janeiro. O clima de Paty de Alferes, de acordo com a classificação de Köppen, é do tipo $\mathrm{Cw}$ subtropical, com chuvas no verão e estiagem no inverno (INMET, 1995). A precipitação média anual para os anos de 2006 a 2011 (período do experimento) foi $1.228 \mathrm{~mm}$, segundo dados da estação meteorológica da Empresa de Pesquisa Agropecuária do Estado do Rio de Janeiro (PESAGRO) localizada em Avelar, Paty do Alferes. De posse dos dados meteorológicos, foi calculado o balanço hídrico da região para o período (Figura 1), de acordo com metodologia proposta por Thornthwaite \& Mather (1955), utilizando-se planilha eletrônica desenvolvida por Sentelhas et al. (1998) e usando-se o valor de $300 \mathrm{~mm}$, como a capacidade de água disponível (CAD) no solo, decorrente da classe de solos da área ser Latossolo Vermelho-Amarelo. Observa-se déficit hídrico a partir do mês de abril até o mês de setembro, com maior acentuação nos meses de agosto e setembro. De novembro a fevereiro ocorre excedente hídrico no solo.

\section{INSTALAÇÃO, CONDUÇÃO E AVALIAÇÃO DO EXPERIMENTO}

O experimento foi instalado em dezembro de 2005 em área pertencente à empresa Rigotex Têxtil, a uma altitude média de 706 metros. A utilização anterior da área era pastagem, com predominância de Melinis minutiflora (capim-gordura) e Imperata exaltata (sapê). Apresenta declividade média de $35 \%$ e análise expedita classificou a textura da camada de $0-40 \mathrm{~cm}$ do solo como argilosa.

Foram utilizadas mudas produzidas em tubetes de $56 \mathrm{~cm}^{3}$ (12 cm de comprimento e $3,5 \mathrm{~cm}$ de diâmetro de "boca") de sete materiais genéticos de eucalipto, os quais constituem os tratamentos. As espécies utilizadas foram Eucalyptus grandis, E. pellita, E. saligna e E. urophylla, procedentes de Anhembi, SP, nível de melhoramento de área de produção de sementes (APS) F1, e também o híbrido Eucalyptus urophylla x E. grandis, procedente de Itirapina, SP, nível de melhoramento de pomar de sementes por mudas (PSM) F2. As sementes desses materiais genéticos foram adquiridas do Instituto de Pesquisas e Estudos Florestais (IPEF) e as mudas, produzidas em viveiro do Estado do Rio de Janeiro. Utilizaram-se também dois clones de Eucalyptus urophylla $\mathrm{x}$ E. grandis cujas mudas foram produzidas por uma empresa em viveiro localizado em Roseira, SP, os quais foram denominados, neste trabalho, de clone amarelo e clone branco.

No início de dezembro de 2005, toda a área foi roçada, com o corte das plantas herbáceas. Com base nas características visuais da área, resultados da análise química do solo (Tabela 1) e conhecimentos gerais sobre as exigências nutricionais de eucalipto foi aplicado calcário calcítico $(\mathrm{CaO}=45 \% ; \mathrm{MgO}=3 \%, \mathrm{PRNT}=87 \%)$ a lanço

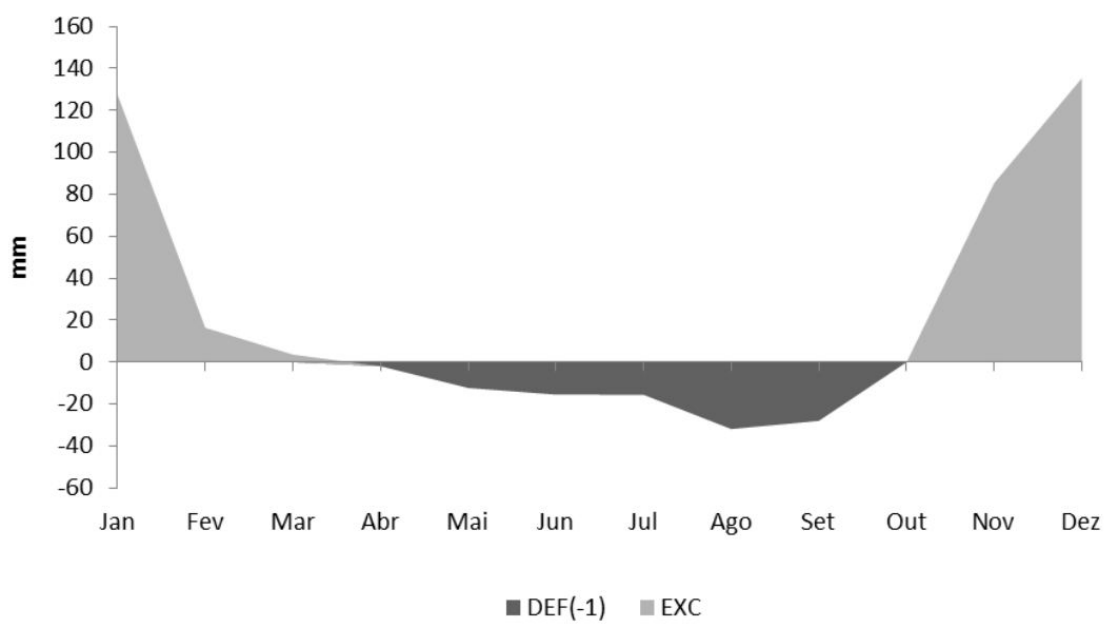

Figura 1. Extrato do balanço hídrico mensal com base em dados de janeiro de 2006 a dezembro de 2011 para o município de Paty do Alferes, RJ.

Figure 1. Extract of hydric balance monthly, based in data from January 2006 to december 2011 for the city of Paty do Alferes, RJ. 
Tabela 1. Análise química da camada de 0-25 cm do solo da área experimental em Paty do Alferes, RJ.

Table 1. Soil chemical analysis of the experimental area, layer of $0-25 \mathrm{~cm}$, in Paty do Alferes, RJ.

\begin{tabular}{|c|c|c|c|c|c|c|c|c|c|}
\hline \multirow{2}{*}{ pH } & $\mathbf{P}$ & $\mathbf{K}^{+}$ & $\mathrm{Ca}^{2+}$ & $\mathrm{Mg}^{2+}$ & $\mathrm{Al}^{3+}$ & $\mathbf{H}+\mathbf{A l}$ & CTC (T) & V & m \\
\hline & \multicolumn{2}{|c|}{$\mathrm{mg} \cdot \mathrm{dm}^{-3}$} & \multicolumn{5}{|c|}{ - } & \multicolumn{2}{|c|}{----- \% ------ } \\
\hline 3,9 & 0,1 & 12,5 & 0,3 & 0,1 & 1,6 & 4,95 & 4,98 & 3 & 98 \\
\hline
\end{tabular}

pH em água, $\mathrm{KCl} \mathrm{e} \mathrm{CaCl}_{2}$ - relação 1:2,5; P e K - Extrator Mehlich 1; Ca, Mg e Al - Extrator: $\mathrm{KCl}$ 1,0 mol/L; H + $\mathrm{Al}$ - Extrator Acetato de Cálcio 0,5 mol/L - ph 7,0; CTC (T) - Capacidade de Troca Catiônica a pH 7,0; V = Îndice de Saturação de Bases; $\mathrm{m}=$ Índice de Saturação de Alumínio.

na área experimental, na dose de 1,5 t.ha ${ }^{-1}$. Em seguida, as covas foram marcadas, no sentido nível do terreno, adotando-se o espaçamento $3 \times 2 \mathrm{~m}$ e realizando-se o coroamento (raio de $80 \mathrm{~cm}$ ). As covas foram abertas manualmente, nas dimensões $25 \times 25 \times 25 \mathrm{~cm}$, foi aplicada adubação de plantio na dose de 200 gramas de N-P-K (04-30-04) + 0,4\% de Zn por cova e em seguida fez-se o plantio das mudas.

O experimento foi instalado adotando-se delineamento em blocos casualizados, com três repetições, totalizando 21 unidades amostrais de 35 mudas cada ( 5 linhas por 7 covas de plantio). Assim, cada unidade experimental foi de $210 \mathrm{~m}^{2}$ (15 x $14 \mathrm{~m}$ ), Como foram 21 unidades amostrais, a área total com o experimento foi de aproximadamente 0,45 hectares. Para não deixar o experimento isolado, o que dificultaria para a empresa a logística das atividades (controle de formigas cortadeiras, controle de plantas daninhas etc.), ele foi inserido em uma área de implantação de povoamento comercial de Eucalyptus pellita de aproximadamente 21 hectares.

Considerando que a taxa de sobrevivência das plantas de eucalipto depende fortemente das condições climáticas (Stape et al., 2010; Borges, 2012), na Tabela 2 são apresentados dados de precipitação total, de temperatura média máxima, de umidade relativa do ar média e o total de insolação das primeiras semanas posteriores ao plantio, entre $1^{\circ}$ e $2^{\circ}$ mês ( $5^{\mathrm{a}}$ a $8^{\mathrm{a}}$ semana) e entre o $3^{\circ}$ e o $6^{\circ}$ mês após o plantio.

A condução do experimento, exceto as avaliações, ocorreu da mesma maneira que a do povoamento comercial, sendo o controle das formigas cortadeiras realizado antes, durante e até 6 meses após o plantio, com uso de isca formicida. O controle das plantas daninhas foi realizado com coroamento aos 45 dias e 6 meses após o plantio, com roçada e coroamento aos 3 e aos 12 meses após o plantio. As adubações de cobertura foram realizadas aos 3, 6 e 12 meses após o plantio (juntamente com controle de plantas daninhas) com aplicação, respectivamente de 60 g, 90 g e 150 g de N-P-K (20-05-20) por planta.

A sobrevivência foi avaliada aos 2 meses após o plantio, contando-se o número de plantas mortas em cada unidade amostral, resultado apresentado em valores percentuais de plantas vivas.

Aos 18 e 80 meses após o plantio foi realizada a medição da circunferência a 1,30 metro da superfície do solo (CAP) e da altura total, desconsiderando-se as plantas das bordaduras de 15 árvores úteis de cada unidade amostral. O CAP foi medido com fita métrica, a primeira medição da altura de 18 meses com vara dendrométrica e a segunda, com hipsômetro. Os dados de CAP foram transformados para diâmetro (DAP).

Na medição realizada aos 80 meses após o plantio, selecionaram-se em cada unidade amostral duas árvores médias (com base nos valores mais próximos dos valores de DAP e altura total médios) para serem abatidas, para realização de cubagem rigorosa e determinação da biomassa de lenho (madeira com casca). Assim, para cada material genético foram abatidas 6 árvores, totalizando 42 árvores cubadas.

As árvores foram desgalhadas e a cubagem rigorosa realizada com a medição da circunferência da árvore a cada $2 \mathrm{~m}$. Em seguida foram retirados discos de $3 \mathrm{~cm}$ de espessura na base, a 25\%, 50\%, 75\% e 100\% da altura comercial (diâmetro $>4,9 \mathrm{~cm}$ ) para medir-se a espessura da casca, a fim de se obter o volume com e sem casca. Em laboratório, calculou-se o volume de cada árvore pelo somatório dos volumes nos intervalos de medição empregados, de acordo com a fórmula de Smalian (Soares et al., 2006).

Com base nos dados de volume médio com casca, foi estimada a produtividade média de madeira de cada material genético aos 80 meses após o plantio. A fim 
Tabela 2. Precipitação total $(\mathrm{P})$, temperatura média máxima $(\mathrm{T})$, umidade relativa do ar média (UR) e total de insolação (I) das primeiras semanas posteriores ao plantio dos sete materiais genéticos de eucalipto em Paty do Alferes, RJ.

Table 2. Total rainfall, maximum average temperature, average air relative humidity and total insolation, of the first weeks after the planting of the seven different genetic materials of eucalypts, in Paty dos Alferes, RJ.

\begin{tabular}{ccccc}
\hline Semana & $\mathbf{P}(\mathbf{m m})$ & $\mathbf{T}\left({ }^{\circ} \mathbf{C}\right)$ & UR (\%) & I (horas) \\
\hline $1^{\text {a }}$ & 61,9 & 25,0 & 83,2 & 13,9 \\
$2^{\text {a }}$ & 39,8 & 29,1 & 73,5 & 37,0 \\
$3^{\text {a }}$ & 23,4 & 28,6 & 77,1 & 41,2 \\
$4^{\text {a }}$ & 29,1 & 29,3 & 75,6 & 45,3 \\
$5^{\text {a }}$ a & 116,2 & 29,6 & 70,2 & 47,6 \\
\hline
\end{tabular}

Fonte: Empresa de Pesquisa Agropecuária do Estado do Rio de Janeiro - Campo experimental de Avelar - $22^{\circ} 21^{\prime}$ S, $43^{\circ} 25^{\prime} \mathrm{W}$, alt.: 507 metros.

de padronizar e comparar, foi estabelecida a taxa de sobrevivência de $95 \%$ para todos os materiais genéticos, considerando assim 1.583 árvores por hectare para se calcular volume e biomassa de lenho por hectare.

Após a medição da circunferência das árvores para a cubagem rigorosa, essas foram cortadas em pedaço,de 0,5 a 2,0 m, para que pudessem ser pesadas em balança no campo.

Os discos foram trazidos no mesmo dia para o laboratório e pesados para obtenção do peso verde do lenho. Esses materiais foram acondicionados em sacos de papel e colocados em estufa a $105^{\circ} \mathrm{C}$, onde permaneceram (4 a 6 dias) até obtenção de peso constante. Em seguida, foram pesados em balança de precisão, obtendo-se o peso de matéria seca das amostras de cada árvore abatida. Com base no peso de matéria verde e de matéria seca das amostras e no peso verde do lenho no campo obteve-se a biomassa de matéria seca do lenho de cada árvore dos materiais genéticos estudados.

Todos os dados foram submetidos a teste de homogeneidade de variância dos tratamentos e de normalidade dos dados, constando não haver necessidade de transformação. Em seguida, foram submetidos à análise de variância, quando detectadas diferenças significativas. As médias foram agrupadas pelo teste de Scott-Knott. Em ambas, considerou-se o nível de 95\% de probabilidade.

Com base no volume aos 80 meses foi calculado o incremento médio anual de lenho de cada material genético, dividindo-se o volume por 6,67 anos.

\section{RESULTADOS E DISCUSSÃO}

As variáveis estudadas não apresentaram diferenças significativas em relação aos blocos, provavelmente devido ao experimento ter sido instalado em uma encosta de declividade aparentemente regular (com poucas oscilações de relevo), em terço médio superior.

Clone Amarelo, clone Branco, Eucalyptus grandis e Eucalyptus urophylla $\mathrm{x}$ E. urophylla apresentaram percentual de sobrevivência de $98,9 \%$ e foram significativamente superiores aos demais materiais genéticos avaliados aos 2 meses após o plantio. Eucalyptus saligna e E. urophylla apresentaram valores de $94,6 \%$ e E. Pellita, de $91,3 \%$, não diferindo significativamente entre si.

Esperava-se que todos os materiais genéticos apresentassem sobrevivência próximo a $100 \%$, pois conforme observa-se pela Figura 1 e pela Tabela 2, até 2 meses após o plantio (período mais crítico para o estabelecimento do povoamento de eucalipto) houve boa incidência de chuvas na região, com excedente de água no solo, fatores que segundo Borges (2012) favorecem o estabelecimento das plantas de eucalipto. Coutinho et al. (2004), testando 10 espécies de eucalipto na Zona da Mata Pernambucana, observaram taxa de sobrevivência superior a 95\% para todas as espécies aos 12 meses após o plantio. O mesmo foi verificado por Drumond et al. (1998) em teste de espécies e procedências de eucalipto nos tabuleiros costeiros de Sergipe, na mesma idade. Autores deste último trabalho atribuíram esse alto valor à boa precipitação na região até os 5 meses após o plantio.

Geralmente, em empresas florestais, o replantio é necessário quando a taxa de mortalidade for maior ou igual a 5\%. Assim, Eucalyptus urophylla $\times$ E. grandis, 
E. saligna, E. urophylla e E. pellita necessitariam de replantio, o que aumenta os custos de formação do povoamento florestal, podendo haver queda na qualidade dos povoamentos com essas espécies, por existir maior percentagem de árvores suprimidas. Esses valores inferiores de sobrevivência dos quatro materiais genéticos indicam que, preliminarmente, esses não se adaptaram bem às condições edafo-climáticas da região onde foi instalado o experimento.

É importante destacar que, em média, a taxa de sobrevivência foi superior a $95 \%$, devido à boa precipitação, aliada aos dias nublados (baixa insolação) e alta umidade relativa do ar na $1^{\text {a }}$ semana após o plantio (Tabela 2). Segundo Stape et al. (2010), as plantas de eucalipto são bastante exigentes em água em todo o ciclo, principalmente na fase de estabelecimento. Borges (2012) mostra que existe correlação negativa entre o estabelecimento de eucalipto e insolação diária. Esses resultados evidenciam a importância de se realizar o plantio em épocas chuvosas e em dias nublados para todos os materiais genéticos.

Constata-se pela Tabela 3 que aos 18 meses após o plantio as médias de diâmetros dos materiais genéticos de Eucalyptus urophylla $\mathrm{x}$ E. grandis foram significativamente superiores a dos demais materiais genéticos, evidenciando a adaptabilidade desse híbrido a região onde foi inserido o experimento. Nessa idade, os clones apresentaram também maior altura. $\mathrm{O}$ rápido crescimento inicial em altura é uma das estratégias para auxiliar no controle das plantas daninhas em povoamentos florestais (Ferreira et al., 2010), evidenciando a importância de se usar materiais genéticos bem adaptados, visando diminuir os custos na formação do povoamento florestal e obter maior produtividade. Segundo Gonçalves et al. (2013), clones advindos de híbridos normalmente apresentam vantagens em relação aos materiais genéticos advindos de sementes (monoespecíficos), pois são mais adaptados às condições climáticas e resistentes a doenças.

O comportamento intermediário de crescimento em diâmetro e altura de E. grandis aos 18 meses provavelmente ocorreu devido à região apresentar déficit hídrico entre maio e setembro (Figura 1), pois segundo Baldwin \& Stewart (1987) e Gonçalves et al. (2013), essa espécie não se adapta bem em regiões com déficit hídrico.

Em média, E. pellita apresentou valores de crescimento significativamente inferiores em ambas as idades, indicando que esta espécie aparentemente não é recomendável para a Região do Médio Paraíba do Sul, RJ. Segundos dados da estação metereológica instalada em Paty do Alferes, nos meses de julho e agosto é comum ocorrerem temperaturas inferiores a $12^{\circ} \mathrm{C}$ no município. Silva (2008), em revisão bibliográfica sobre espécies de eucalipto tolerantes a baixas temperaturas, menciona que E. pellita não suporta regiões de clima frio, podendo-se inferir que esse fato contribuiu para que essa espécie apresentasse os menores valores de crescimento entre os materiais genéticos testados em ambas as idades. Em trabalho de revisão sobre materiais genéticos de eucalipto, Gonçalves et al. (2013) mencionam que E. pellita, na Região Sudeste do Brasil, é considerada espécie de crescimento regular, sendo E. grandis de crescimento

Tabela 3. Valores médios de altura total e de diâmetro à altura de 1,30 metro da superfície do solo (DAP) de sete materiais genéticos de eucalipto aos 18 meses e aos 80 meses após o plantio em Paty do Alferes, RJ.

Table 3. Mean of values of height and diameter at 1.30 meter from of the soil (DAP) of seven genetic materials eucalyptus at 18 months and 80 months after planting, grown in Paty do Alferes, RJ.

\begin{tabular}{|c|c|c|c|c|}
\hline \multirow{2}{*}{$\begin{array}{l}\text { Material genético } \\
\text { de eucalipto }\end{array}$} & \multicolumn{2}{|c|}{ 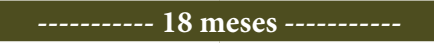 } & \multicolumn{2}{|c|}{---------- 80 meses ---------- } \\
\hline & Altura (m) & $\operatorname{DAP}(\mathrm{cm})$ & Altura (m) & $\mathrm{DAP}(\mathrm{cm})$ \\
\hline E. grandis & $6,1 \mathrm{~b}$ & $4,8 \mathrm{~b}$ & $24,1 \mathrm{a}$ & $15,2 \mathrm{a}$ \\
\hline E. saligna & $5,2 \mathrm{~d}$ & $4,5 \mathrm{~b}$ & $20,3 b$ & $15,1 \mathrm{a}$ \\
\hline Clone Amarelo* & $6,5 \mathrm{a}$ & $5,1 \mathrm{a}$ & $23,4 \mathrm{a}$ & $15,0 \mathrm{a}$ \\
\hline Clone Branco* & $6,7 \mathrm{a}$ & $5,3 \mathrm{a}$ & $23,5 \mathrm{a}$ & $14,4 \mathrm{a}$ \\
\hline E. urograndis ${ }^{\star *}$ & $6,2 \mathrm{~b}$ & $5,2 \mathrm{a}$ & $21,6 \mathrm{~b}$ & $14,3 \mathrm{a}$ \\
\hline E. urophylla & $5,7 \mathrm{c}$ & $4,7 \mathrm{~b}$ & $19,7 \mathrm{~b}$ & $14,1 \mathrm{a}$ \\
\hline E. pellita & $4,6 \mathrm{e}$ & $3,7 \mathrm{c}$ & $16,7 \mathrm{c}$ & $10,1 \mathrm{~b}$ \\
\hline
\end{tabular}

${ }^{\star}$ Proveniente de estaquia de Eucalyptus urophylla $\mathrm{x}$ E. grandis; ${ }^{*}$ Eucalyptus urophylla $\mathrm{x}$ E. grandis, proveniente de sementes; Médias seguidas pela mesma letra, na coluna, não diferem entre si, pelo Teste de Scott-Knott, a 95\% de probabilidade. 
Tabela 4. Características de crescimento de materiais genéticos de eucalipto aos 80 meses após o plantio, cultivados em Paty do Alferes, RJ.

Table 4. Growth characteristics of genetic materials eucalyptus at 80 months after planting, grown in Paty do Alferes, RJ.

\begin{tabular}{|c|c|c|c|c|c|}
\hline \multirow{2}{*}{$\begin{array}{c}\text { Material genético } \\
\text { de eucalipto }\end{array}$} & \multicolumn{2}{|c|}{ Volume ( $\mathrm{m}^{3}$ /árvore) } & \multirow{2}{*}{$\frac{\text { Lenho*** }}{\text { (kg/árv.) }}$} & \multicolumn{2}{|c|}{ Por hectare } \\
\hline & Com casca & Sem casca & & Volume $\left(\mathrm{m}^{3}\right)$ & Lenho*** (ton.) \\
\hline E. grandis & $0,20 \mathrm{a}$ & $0,16 \mathrm{a}$ & $121,4 \mathrm{a}$ & $318,4 \mathrm{a}$ & $192,1 \mathrm{a}$ \\
\hline Clone Amarelo* & $0,18 \mathrm{a}$ & $0,16 \mathrm{a}$ & $120,5 \mathrm{a}$ & $284,5 \mathrm{a}$ & $190,8 \mathrm{a}$ \\
\hline E. urograndis $* *$ & $0,18 \mathrm{a}$ & $0,15 \mathrm{a}$ & $132,1 \mathrm{a}$ & $286,4 \mathrm{a}$ & $209,2 \mathrm{a}$ \\
\hline Clone Branco* & $0,15 \mathrm{~b}$ & $0,13 \mathrm{~b}$ & $77,5 \mathrm{~b}$ & $234,8 \mathrm{~b}$ & $122,7 \mathrm{~b}$ \\
\hline E. saligna & $0,14 \mathrm{~b}$ & $0,12 \mathrm{~b}$ & $74,3 \mathrm{~b}$ & $225,9 \mathrm{~b}$ & $117,6 \mathrm{~b}$ \\
\hline E. urophylla & $0,13 \mathrm{~b}$ & $0,11 \mathrm{~b}$ & $62,9 \mathrm{~b}$ & $212,2 \mathrm{~b}$ & $99,5 \mathrm{~b}$ \\
\hline E. pellita & $0,08 \mathrm{c}$ & $0,06 \mathrm{c}$ & $44,1 \mathrm{~b}$ & $121,6 \mathrm{c}$ & $69,7 \mathrm{~b}$ \\
\hline
\end{tabular}

${ }^{*}$ Proveniente de estaquia de Eucalyptus urophylla x E. grandis; ${ }^{*}$ Eucalyptus urophylla $\mathrm{x}$ E. grandis, proveniente de sementes; *** Madeira + casca; Médias seguidas pela mesma letra não diferem entre si pelo Teste de Scott-Knott, a 95\% de probabilidade.

ótimo e E. urophylla de crescimento bom, o que foi confirmado neste trabalho.

Drumond et al. (1998), ao realizarem teste de espécies e procedências de eucalipto na Região de Tabuleiros Costeiros do Estado de Sergipe, constataram que E. pellita, aos 12 meses após o plantio, estava no grupo das espécies de melhor crescimento, com valores médios de DAP de $4,3 \mathrm{~cm}$, superiores ao deste trabalho aos 18 meses, evidenciando que essa espécie não apresentou bom crescimento inicial em Paty do Alferes, RJ.

Pela Tabela 3 observa-se também que aos 80 meses apenas E. pellita foi estatisticamente inferior, com $10,0 \mathrm{~cm}$ de DAP. Os demais materiais genéticos fizeram parte de um único grupo. Isso demonstra que, no decorrer do tempo, a maioria dos materiais genéticos conseguiu obter bom crescimento, com valores médios em torno de $15 \mathrm{~cm}$. Drumond et al. (1998), trabalhando com E. grandis, E. pellita e E. Urophylla, e Magalhães et al. (2007), com E. camaldulensis, E. pellita e E. Urophylla, não observaram diferenças significativas de DAP aos 8,0 e 9,4 anos após o plantio, respectivamente. Esses trabalhos evidenciam que o ambiente tem menor influência no crescimento na fase adulta do que na fase de estabelecimento das plantas de eucalipto (sobrevivência e crescimento inicial).

Para o crescimento em altura média, aos 80 meses, constata-se que o clone Branco $(23,5 \mathrm{~m})$ e o clone Amarelo (23,4 m) mantiveram sua superioridade desde a fase inicial e foram alcançados em crescimento por E. grandis $(24,1 \mathrm{~m})$. Isso indica que essa espécie foi capaz de, no período de 18 a 80 meses, utilizar melhor os recursos edafoclimáticos do ambiente, a ponto de se igualar aos dois clones aos 80 meses.

Verifica-se na Tabela 4 que E. grandis, clone Amarelo e Eucalyptus urophylla $\mathrm{x}$ E. grandis foram significativamente superiores para as características volume e biomassa de lenho aos 80 meses após o plantio em relação aos demais materiais genéticos. Esperava-se que clone Branco também estivesse presente nesse grupo dos materiais genéticos de maior produção. Isso provavelmente não ocorreu devido a erro de escolha de árvore(s) modelo(s) para cubagem rigorosa e determinação de biomassa do lenho (madeira + casca).

Ao se calcular o incremento médio anual, obteve-se valores de 47,7 $\mathrm{m}^{3}, 42,7 \mathrm{~m}^{3}$ e 43,0 $\mathrm{m}^{3} \mathrm{ha}^{-1}$ ano $^{-1}$, respectivamente para E. grandis, clone Amarelo e Eucalyptus urophylla $\mathrm{x} E$. grandis, superiores à média nacional do gênero eucalipto no Brasil, que é de 40,1 $\mathrm{m}^{3}$ ha $^{-1}$ ano $^{-1}$ (ABRAF, 2013). Para E. Pellita, esse valor foi de $18,2 \mathrm{~m}^{3}$, não sendo indicado para cultivo na Região do Médio Paraíba do Sul, RJ. Demais matérias obtiveram valores que variaram de $35,2 \mathrm{~m}^{3}$ a $31,8 \mathrm{~m}^{3} \cdot \mathrm{ha}^{-1}$. ano ${ }^{-1}$. Trabalhos evidenciam que E. pellita apresenta crescimento relativamente inferior a outras espécies de eucalipto. Gomes et al. (1981), comparando o crescimento de 57 espécies e procedências de eucalipto aos 6,5 anos após o plantio, em 30 localidades de Minas Gerais e São Paulo, constataram que os materiais genéticos de E. grandis estão entre os que apresentaram maior crescimento. Verificaram também que E. saligna está no bloco intermediário superior e que E. pellita está no bloco intermediário inferior, em termos de crescimento, quando comparados com 
as outras espécies. Bernardo et al. (1998) observaram na região de Cerrado de Minas Gerais, que apresenta elevado déficit hídrico no solo na maior parte do ano, que E. urophylla apresentou maior crescimento do que E. pellita aos 41 meses após o plantio nos três espaçamentos testados, atribuindo tal fato ao crescimento radicular mais profundo da primeira espécie.

\section{CONCLUSÕES}

Entre os materiais genéticos avaliados, Eucalyptus grandis, clone Amarelo e Eucalyptus urophylla $\mathrm{x}$ grandis, em termos de crescimento e produção, são os mais recomendados para cultivo na Região do Médio Paraíba do Sul, sendo E. pellita o menos recomendado.

\section{AGRADECIMENTOS}

Os autores agradecem à Rigotex Industrial Textil Ltda pela instalação, manutenção e apoio para realização do trabalho

\section{STATUS DA SUBMISSÃO}

Recebido: 3 fev., 2015

Aceito: 26 jun., 2016

\section{AUTOR(ES) PARA CORRESPONDÊNCIA}

\section{Paulo Sérgio dos Santos Leles}

Departamento de Silvicultura, Instituto de Florestas, Universidade Federal Rural do Rio de Janeiro - UFRRJ, CEP 23890-000, Seropédica, RJ, Brasil

e-mail:pleles@ufrrj.br

\section{REFERENNCIAS}

Amorim HB, Francelino MR, Salamene S, Pedreira LOL, Assumpção LI Fo, Capitano RC et al. Estimativa da área ocupada por reflorestamentos no Estado do Rio de Janeiro. Cerne 2012; 18(1): 27-32. http://dx.doi.org/10.1590/ S0104-77602012000100004.

Associação Brasileira de Produtores de Florestas Plantadas - ABRAF. Anuário estatístico da ABRAF. Brasília: ABRAF; 2013 [citado em 2014 jan 10]. 167 p. Disponível em: http:www.abraflor.org. br/estatisticas.asp.

Baldwin PJ, Stewart HTL. Distribution, lenght and wight of roots in young plantations of Eucalyptus grandis W. Hill ex
Maiden irrigated with recycled water. Plant and Soil 1987; 97(2): 243-252. http://dx.doi.org/10.1007/BF02374947.

Barros NF, Cardoso JR, Macedo PRO. Algumas relações solo-eucalipto em suas condições naturais. In: Barros NF, Novais RF, editores. Relação solo eucalipto. Viçosa: Folha de Viçosa; 1990.

Bernardo AL, Reis MGF, Reis GG, Harrison RB, Firme DJ. Effect of spacing on growth and biomass distribution in Eucalyptus camaldulensis, E. pellita and E. urophylla plantations in southeastern Brazil. Forest Ecology and Management 1998; 104(1-3): 1-13. http://dx.doi.org/10.1016/ S0378-1127(97)00199-0.

Borges JS. Modulador edáfico para uso em modelo ecofisiológico e produtividade potencial de povoamentos de eucalipto [tese]. Viçosa: Universidade Federal de Viçosa; 2012.

Coutinho JLB, Santos VF, Ferreira RLC, Nascimento JCB. Avaliação do comportamento de espécies de Eucalyptus spp. na Zona da Mata Pernambucana. I: resultados do primeiro ano - 2001. Revista Árvore 2004; 28(6): 771-775. http://dx.doi.org/10.1590/S0100-67622004000600001.

Del Quiqui EM, Martins SS, Shimizu JY. Avaliação de espécies e procedências de Eucalyptus para o Noroeste do Estado do Paraná. Acta Scientiarum 2001; 23(5): 1173-1177.

Drumond MA, Oliveira VR, Carvalho OM. Comportamento silvicultural de espécies e procedências de Eucalyptus na região dos tabuleiros costeiros do Estado de Sergipe. Revista Árvore 1998; 22(1): 133-142.

Federação das Indústrias do Estado do Rio de Janeiro FIRJAN. Contribuições ao Desenvolvimento da Silvicultura Econômica no Estado do Rio de Janeiro. Rio de Janeiro: FIRJAN; 2013 [citado em 2014 set 16]. 14 p. Disponível em: http://www.firjan.org.br.

Ferreira LR, Machado AFL, Ferreira FA, Santos LDT. Manejo Integrado de Plantas Daninhas na cultura do Eucalipto. Viçosa: UFV; 2010.

Gomes JM, Pereira AR, Brandi RM, Maciel LAF. Variação do crescimento de espécies e procedências de eucalipto cultivadas na região de Viçosa, MG. Revista Árvore 1981; 5(2): 233-249.

Gonçalves JLM, Alvares CA, Higa AR, Silva LD, Alfenas $\mathrm{AC}$, Stahl $\mathrm{J}$ et al. Integrating genetic and silvicultural strategies to minimize abiotic and biotic constraints in Brazilian eucalypt plantations. Forest Ecology and Management 2013; 23(1): 6-27. http://dx.doi.org/10.1016/j. foreco.2012.12.030

Instituto Brasileiro de Geografia e Estatística - IBGE. Contas regionais do Brasil 2012. Rio de Janeiro: IBGE; 2014. n. 42, 55 p.

Instituto Nacional de Meteorologia - INMET. Boletim Agrometeorológico (1974-1993) [Relatório Interno]. Brasília; 1995. 
Magalhães WM, Macedo RLG, Venturin N, Higashikawa EM, Yoshitani JRM. Desempenho silvicultural de clones e espécies/procedências de Eucalyptus na região noroeste de Minas Gerais. Cerne 2007; 13(4): 368-375.

Martinez DT, Higa AR, Lingnau C, Silva IC. Escolha de espécies, planejamento e sistemas de produção para reflorestamento em pequenas propriedades no estado do Paraná. Curitiba: FUPEF; 2012.

Morais EJ, Barros NF, Brandi RM. Biomassa e eficiência nutricional de espécies de eucalipto em duas regiões bioclimáticas de Minas Gerais. Revista Brasileira de Ciência do Solo 1990; 14(2): 353-362.

Poyry Silviconsult. Estudo de mercado: consumo de produtos de base florestal [Relatório Técnico]. Curitiba; 2012.

Rio de Janeiro. Governo do Estado. Assembléia Legislativa Lei n 5067 de 09 de julho de 2007. Dispõe sobre o zoneamento ecológico-econômico do Estado do Rio de Janeiro. Rio de Janeiro: Governo do Estado do Rio de Janeiro; 2007 [citado em 2014 set 16]. Disponível em: http://www.alerj.rj.gov. br/processo2.htm.

Sentelhas PC, Pereira AR, Marin FR. BHBRASIL: balanços hídricos climatológicos de 500 localidades brasileiras.
Piracicaba: ESALQ; 1998 [citado em 2014 ago. 11]. Disponível em: http://www.lce.esalq.usp.br/nurma.html.

Silva LD. Melhoramento genético de Eucalyptus benthamii Maiden et Cambage visando a produção de madeira serrada em áreas de ocorrência de geadas severa [tese]. Curitiba: Universidade Federal do Paraná; 2008. 87 f.

Soares CPB, Paula Neto F, Souza AL. Dendrometria e inventário florestal. Viçosa: UFV; 2006. 276 p.

Stape JL, Binkley D, Ryan MG, Fonseca RA, Loos RA, Takahashi EN et al. The Brazil eucalyptus potential productivity project: influence of water, nutrients and stand uniformity on wood production. Forest Ecology and Management 2010; 259(9): 1684-1694. http://dx.doi. org/10.1016/j.foreco.2010.01.012.

Sturion JA, Bellote AFJ. Implantação de povoamentos florestais com espécies de rápido crescimento. In: Galvão APM. Reflorestamento de propriedades rurais para fins produtivos e ambientais. Colombo: Embrapa Florestas; 2000. p. 209-219.

Thornthwaite CW, Mather JC. The water balance. Centeron: Drexel Institute of Technology; 1955. 104 p. 